\title{
EDUCANDO À DIREITA: MERCADOS, PADRÕES, DEUS E DESIGUALDADE*
}

Salomão Mufarrej Hage**

$\mathcal{E}$ ste livro vem somar-se ao conjunto de publicações em que Michael Apple, nestes últimos dez anos, analisa os movimentos conservadores que têm reconstruído a educação de formas perniciosas. Por meio dele podemos compreender que a influência que essas posições têm hoje sobre a sociedade em geral e sobre a política e a prática educacional em particular não diminuiu, ao contrário: intensificou-se e arraigou-se mais ainda no senso comum da sociedade estadunidense (e de muitas outras).

Apple fundamenta seus argumentos não somente no debate do mundo acadêmico, mas a partir da utilização de um número considerável de evidências nacionais e internacionais sobre os efeitos das políticas correntes da educação; de sua participação em movimentos contra a reestruturação radicalmente conservadora da educação em muitas nações; de experiências que são uma evidência da natureza absolutamente fantástica das vidas e esperanças que serão perdidas se não continuarmos a batalha contra essas políticas; e, por fim, de sua própria indignação contra a arrogância daqueles que acreditam tanto na lógica do mercado que não conseguem enxergar os danos que essa arrogância cria no mundo real.

Seguindo essa lógica mercadológica, grande parte dos eruditos, políticos, dirigentes de grandes empresas e outros consideram a edu-

\footnotetext{
* Resenha do livro de Michael Apple (São Paulo: Cortez/ Instituto Paulo Freire, 2003. Biblioteca Freireana, v. 5).

* Doutor em Educação pela Pontifícia Universidade Católica de São Paulo (PUC-SP) e pela Universidade de Wisconsin (Madison, EUA), e professor adjunto do Centro de Educação da Universidade Federal do Pará (UfPA). E-mail: salomao@ uol.com.br
} 
cação um negócio que não deve ser tratado de forma diferente de nenhum outro negócio, e têm conseguido fazer com que essa posição venha se tornando cada vez mais comum, o que é preocupante em sua visão, pois, dentre as muitas vozes que falam agora sobre educação, só as mais poderosas tendem a ser ouvidas; e embora não exista nenhuma posição unitária que centralize aqueles que têm poder político, econômico e cultural, as tendências mais importantes em torno da qual gravitam aparentam ser mais conservadoras que progressistas.

No livro, Apple indica o que essas vozes mais poderosas e conservadoras estão dizendo e fazendo: eles têm feito pressão para obter fundos para escolas privadas e religiosas, colocando os planos de financiamento estudantil à frente desse movimento; eles acreditam que só obrigando as escolas a estarem num mercado competitivo é que vai haver algum tipo de melhoria; que não há "fatos" no currículo; que os conteúdos e métodos tradicionais têm sido descartados, à medida que nossas escolas se voltam para disciplinas mais em moda (e exageradamente multiculturais) que ignoram o saber que fez dos Estados Unidos uma grande nação; que é necessário melhorar o padrão de qualidade e introduzir mais provas nas escolas, com base em conhecimentos "reais"; aumentar o grau de exigência com relação a professores e alunos reprovados... Essas medidas vão garantir que as escolas voltem ao conteúdo e aos métodos tradicionais consagrados; e se as provas e os conteúdos não forem o bastante, é necessário criar e impor leis relativas aos métodos e ao conteúdo de âmbito estadual.

Todas essas medidas se encontram "rodopiando" ao mesmo tempo e sempre que se começa a entender um conjunto de pressões, aparece outro vindo de outra direção. Todas indicam "a" resposta: "E preciso nos tornar verdadeiros adeptos e aplicá-la”. Todas essas pressões estão situadas dentro de uma dinâmica maior e Apple, ao escrever esse livro, propõe-se a "parar esse redemoinho" durante algum tempo para entender seu sentido, tanto na educação quanto em sua relação com forças ideológicas e econômicas maiores em sociedades como a estadunidense.

Ciente de que essas pressões e essas forças são complicadas, Apple começa o processo de entendimento desse "redemoinho" de maneira simples, com a história de uma criança empobrecida (Joseph) de uma sala de aula situada num edifício deteriorado da cidade de East Coast e do relacionamento dela com seu professor. Ele conta como a experiência de fracasso escolar desse menino (que era similar à de muitos outros dessa escola e de muitas outras nos Estados Uni- 
dos) acabava responsabilizando o professor, seus pais e as próprias crianças, fazendo-o desconfiar do enfoque incessante no padrão de qualidade, em mais provas, nos planos de financiamento estudantil, e em outros tipos de "reformas" educacionais que podem parecer boas em termos abstratos, mas que muitas vezes funcionam de maneira exatamente oposta quando chegam à sala de aula.

Em sua busca de entendimento desse "redemoinho", Apple adverte-nos que enfrentamos um amplo movimento de modernização conservadora, que se constitui numa aliança poderosa - embora estranha - entre forças que agora estão em atividade na educação, as quais muitos educadores, ativistas comunitários, pesquisadores críticos e outros acreditam ser ameaças substanciais à vitalidade de nosso país (e de muitos outros no mundo todo), de nossas escolas, de nossos professores e de nossas crianças. Esse movimento recomenda que devemos "libertar" nossas escolas, colocando-as dentro de um mercado competitivo, restaurar "nossa" cultura tradicional comum e enfatizar a disciplina e 0 caráter, voltar-nos para D eus em nossa sala de aula, como guia de toda a nossa conduta dentro e fora da escola, e intensificar o controle central por meio de critérios de avaliação e testes mais rigorosos e exigentes em termos intelectuais. A educação é entendida como sendo apenas a transmissão de um conhecimento neutro aos alunos e 0 papel fundamental da escolarização é encher os estudantes com o conhecimento necessário para competir no mundo de hoje, que está em processo de transformação rápida. 0 currículo também é tido como neutro e está ligado a um sistema neutro de avaliação, que por sua vez está ligado a um sistema de finanças escolares que, quando funcionam bem, garantem a recompensa do mérito. "Bons" alunos assimilam "bons" conhecimentos e conseguem "bons" empregos.

Segundo Apple, esse conceito de boa escola, boa administração e bons resultados tem muitos defeitos; e suas afirmações básicas sobre 0 conhecimento neutro são simplesmente equivocadas, pois existe um conjunto intrincado de ligações entre saber e poder que precisam ser consideradas para que possamos compreender criticamente os desdobramentos dessas afirmações. Ele tem insistentemente reafirmado que questões relativas ao saber de quem, escolhido por quem, como isso é justificado são constitutivas, não "acréscimos" que têm o status de conclusões a que alguém chegou depois de pensar melhor. Em suas análises, ele tem constatado que, na prática, existe um descompasso evidente entre as promessas de escolarização e a criação real de empregos em nossa gloriosa economia supostamente de livre mercado; e esse concei- 
to de boa educação não só marginaliza a política do saber como também oferece pouco aos alunos, aos professores e aos membros da comunidade, tendendo à exacerbação das divisões de raça, gênero e classe que caracterizam tão profundamente essa sociedade.

No livro, embora admita que possa haver problemas com as categorias tradicionais de "esquerda" e de "direita" na organização das complexidades da política real de todas as nações, Apple posiciona-se conscientemente à esquerda, por considerar que ela mantém a vitalidade dos Estados Unidos (e de muitos outros países). No entanto, ele nos chama atenção de que, nos Estados Unidos, boa parte da direita também se encontra profundamente envolvida com transformaçoes radicais e, ao longo das últimas décadas, tem lançado um ataque conjunto sobre 0 que muitos de nós considerávamos natural, colocando em questão toda a esfera pública e as próprias instituições educacionais.

Por esse motivo, Apple dedica esse livro a uma análise das crenças, propostas e dos programas educacionais direitistas e a seus efeitos no mundo real, justificando sua dedicação a partir de uma afirmação política particular: "O s movimentos sociais direitistas estão excepcionalmente poderosos agora, e um dos elementos mais importantes para saber como detê-los é compreender o que fizeram e estão fazendo".

Apple alerta-nos também para o fato de que a direita nos Estados unidos não é um movimento unitário, mas uma coalizão de forças com muitas ênfases diferentes; algumas têm áreas comuns e outras conflitam entre si. Por esse motivo, um de seus objetivos centrais ao escrever esse livro é examinar as contradições dentro desse movimento, demonstrando como essas tensões são resolvidas para levar nossa sociedade a mudar de fato - mas em certas direções, que não ajudam, de maneira alguma, em longo prazo, crianças como Joseph.

Em contrapartida, embora Apple discorde profundamente de muitas propostas conservadoras para a educação, ele considera tolice defender irracionalmente as escolas como elas se encontram hoje e nos adverte que um dos motivos pelos quais as pessoas ouvem cuidadosamente as críticas direitistas é que existem problemas nessas instituições, e mais, que reconhecer a existência de problemas não significa de modo algum considerar que as "soluções" conservadoras sejam boas.

Ao analisar a atuação direitista, Apple constata que uma de suas principais intenções é mudar nosso senso comum, alterando o significado das categorias mais básicas que empregamos para compreender 0 mundo social e educacional e nosso lugar nele, o que se relaciona 
diretamente à política de identidade. Segundo Apple, a direita tem se concentrado em alterar radicalmente aquilo que pensamos ser e como nossas principais instituições devem responder a essa alteração de identidade. Compreender isso é importante, principalmente porque "quem somos" e "o que pensamos a respeito de nossas instituições" são conceitos intimamente ligados a quem tem o poder de produzir e de fazer circular novas formas de fazer compreender nossa identidade.

Apple chama-nos a atenção para o fato de que os conceitos que usamos para tentar compreender o mundo em que vivemos hoje e para agir nele não determinam por si as respostas que podemos encontrar, na medida em que essas respostas não são determinadas pelas palavras, mas sim pelas relações de poder que impõem sua interpretação desses conceitos. No entanto, ele reconhece que existem palavras-chave que vêm constantemente à tona nos debates sobre educação e reconhece que essas palavras têm suas próprias histórias, que são complicadas, que são cada vez mais inter-relacionadas e que estão ligadas aos movimentos sociais dos quais surgiram e nos quais elas participam dos debates de hoje. Na verdade, essas palavras constituem o subtítulo desse livro: mercados, padrões, D eus e desigualdade. Por trás de cada um desses tópicos, há um outro grupo de palavras que tem valor afetivo e que serve de base de sustentação para as formas segundo as quais o poder diferencial atua em nossa vida cotidiana. Esses conceitos incluem democracia, liberdade, opcão, moralidade, família, cultura e uma série de outros conceitos-chave. E cada um desses, por sua vez, é intertextual. Todos eles estão ligados a uma série de pressupostos sobre instituições, valores, relações sociais e políticas "apropriadas".

De forma criativa e didática, Apple analisa essa situação complexa, relacionando-a a um "mapa rodoviário", em que o uso de uma palavra-chave (por exemplo: mercados) indica às pessoas uma via expressa que segue numa direção e que tem saídas em certos lugares, mas não em outros. Se as pessoas tomarem a via expressa chamada mercado, sua direção geral os levará a uma parte do país chamada economia. Se elas tomarem a saída intitulada individualismo serão conduzidas a uma outra estrada chamada opcão do consumidor. Saídas com palavras como sindicatos, liberdade coletiva, 0 bem comum, política e outros destinos semelhantes são evitadas, quando chegam a existir no mapa. A primeira estrada é um itinerário simples com um único objetivo - decidir para onde uma pessoa quer ir sem uma discussão que implique grande perda de tempo e chegar lá pelo método mais rápido e mais barato possível. Mas há um segundo itinerário, e ele envolve muita deliberação 
coletiva sobre o lugar para onde poderíamos ir. Pressupõe que deve haver uma certa parcela de deliberação constante a respeito não só do objetivo, mas também do próprio itinerário. Suas saídas são aquelas que foram evitadas no primeiro itinerário.

De acordo com as análises de Apple, grandes interesses criaram o mapa rodoviário e seus itinerários. Alguns querem somente a estrada chamada mercado, porque leva supostamente à opção individual. $\mathrm{Ou}$ tros vão tomar essa estrada, mas somente se as saídas forem aquelas que têm uma longa história de "verdadeira cultura" e de "verdadeiro saber". O utros ainda vão tomar a estrada do mercado porque, para eles, D eus disse que essa era a "Sua" estrada. E, por fim, outro grupo vai participar dessa viagem porque tem habilidade para fazer mapas e para determinar a distância que estamos de nosso objetivo. Há pouca discussão e concessão, talvez até alguma tensão prolongada entre esses vários grupos, sobre quais as saídas que acabarão tomando, mas, em geral, todos eles têm seguido uma mesma direção.

Por meio desse exercício de imaginação, Apple mapeia a realidade indicando a configuração dos grupos incluídos na aliança direitista que têm indicado a direção das políticas educacionais nos Estados Unidos. Segundo ele, o primeiro grupo é formado pelos neoliberais, que estão profundamente comprometidos com mercados e com a liberdade como "opção individual". 0 segundo grupo, os neoconservadores, tem a visão de um passado hedênico e quer um retorno à disciplina e ao saber tradicional. 0 terceiro, os populistas autoritários, é formado pelos fundamentalistas religiosos e evangélicos conservadores que querem um retorno a (seu) Deus em todas as nossas instituições. E, por fim, os desenhistas de mapas e especialistas em dizer se chegamos ou não a nosso destino são membros de uma fração particular da nova classe média de gerentes e de profissionais qualificados.

Ao analisar essa complexa configuração de interesses da direita, Apple pretende examinar as presenças ausentes, ou seja, "aquilo que não existe" na grande maioria das políticas direitistas para a educação, fazendo uma série de questionamentos que o auxiliem na elucidação de: como é que a linguagem desses grupos atua no sentido de mostrar certas coisas como os "verdadeiros" problemas ao mesmo tempo em que marginalizam outros? Q uais são as conseqüências das políticas que promoveram? Como as políticas aparentemente contraditórias que surgiram das várias frações em luta conseguiram mesclar-se de formas criativas para impor muitos aspectos dessas plataformas direitistas? 
Ao longo dos capítulos em que o livro se encontra distribuído, as respostas a esses questionamentos revelam a estranha combinação de mercados, retorno às tradições e aos valores perdidos, educação religiosa e gerencialismo dos critérios rigorosos e garantia de "qualidade". Neste processo, Apple pretende demonstrar quais grupos de pessoas vão acabar ganhando ou perdendo à medida que essa constelação de "reformas" se concretiza. E aborda essas questões numa perspectiva internacional para chamar atenção do povo dos Estados Unidos não só para a pesquisa e as discussões sobre o que está acontecendo lá como também para as reformas semelhantes que surgiram em outras nações.

No primeiro capítulo, Apple descreve as direções gerais que a sociedade estadunidense tomou. Ele emprega conceitos-chave, como o de liberdade, para analisar a dinâmica ideológica que serve de base de sustentação para essas direções. No Capítulo 2, ele enfoca as posições educacionais de cada um dos grupos que ele identificou, dando um sentido mais claro às tensões e contradições dos movimentos conservadores. No Capítulo 3, Apple trata dos efeitos reais que "reformas" como a instituição de um mercado competitivo na educação, nos currículos nacionais e estaduais, na melhoria do padrão de qualidade e no número crescente de provas obrigatórias tiveram nas escolas de um grande número de países. Esse capítulo também examina as formas pelas quais as alternativas a essas promessas, que giram em torno da literatura sobre "pedagogia crítica", são falhas em aspectos cruciais e, por isso, vão enfrentar muitas dificuldades para deter as transformações direitistas. Segundo Apple, essa literatura muitas vezes não esteve suficientemente conectada às formas pelas quais 0 atual movimento de modernização conservadora alterou o senso comum e transformou as condições materiais e ideológicas em torno do ensino. Isso faz com que, às vezes, ela assuma uma forma do que ele vem chamando de retórica "possibilitariana romântica" em lugar da possibilidade, substituindo uma análise tática consistente de como se encontra 0 equilíbrio de forças e do que é necessário para mudá-lo.

Nos Capítulos 4 e 5 Apple trata do poder crescente dos grupos religiosos conservadores nos debates sobre os fins e os meios da educação, analisando a gênese histórica desses movimentos e as conseqüências relacionadas ao seu crescimento; também elucida as maneiras pelas quais as opiniões desses movimentos sobre currículo e pedagogia se harmonizam com suas posturas mais abrangentes no que diz respeito a economia, governo, família, relações de gênero e política de classe e raça, mesmo que pareçam repressivas para alguém de fora 
deles. No Capítulo 6, Apple examina as maneiras pelas quais o movimento de ensino doméstico oferece um mecanismo para que muitas dessas ênfases se combinem, analisando criticamente seus impulsos sociais, ideológicos e educacionais, bem como uma série de "custos invisíveis" advindos de seu crescimento nos Estados Unidos.

No Capítulo 7, ele avalia as possibilidades de deter a guinada para a direita e sugere algumas estratégias para isso, como "tornar públicos os questionamentos às reivindicações direitistas", enfrentando-os na mídia, nas publicações acadêmicas e profissionais e na vida cotidiana; e "tornar práticas as práticas educacionais críticas", apresentando respostas reais a problemas práticos reais da educação. Apple sugere que possamos mostrar lutas vitoriosas para construir uma educação crítica e democrática em escolas reais e em comunidades reais com professores e alunos reais hoje, dirigindo nossa atenção para as escolas locais de ensino fundamental e médio, em comunidades muito parecidas com aquelas em que a maioria dos norte-americanos estudou. Em seu entendimento, tornar públicas essas histórias faz com que a educação crítica pareça realmente factível e não apenas uma visão utópica sonhada pelos "teóricos críticos" da educação. Repetidamente ao longo de todo 0 livro, Apple dá exemplos de intervenções políticas/ educacionais dessa natureza, indicando serem elas cruciais se tivermos por intenção realmente deter a direita.

Ao longo de todo o livro, Apple procurou esclarecer os elementos de bom-senso e não apenas os absurdos que existem no interior das várias facções da aliança direitista. Ele fez isso para demonstrar que as pessoas que acham certos elementos da modernização conservadora relevantes para sua vida não são simples marionetes que têm pouca compreensão das "verdadeiras" relações de nossa sociedade. Ao contrário, ele pretende afirmar que alguns dos argumentos das facções desse novo bloco hegemônico são ouvidos justamente porque estão conectados com aspectos da realidade que as pessoas vivem, o que significa dizer que a aliança tensa entre essas várias facções só funciona porque tem havido uma articulação muito criativa de temas que ressoam profundamente em experiências, temores, esperanças e sonhos das pessoas em sua vida cotidiana. Com isso, Apple pretende ressaltar que a modernização conservadora tem remodelado radicalmente 0 senso comum das pessoas, atuando em todas as esferas - a econômica, a política e a cultural - para alterar as categorias básicas que usamos para avaliar nossas instituições e nossas vidas pública e privada. Esse movimento reconheceu que, para vencer no Estado, era 
preciso vencer na sociedade civil e, para isso, a realização de um projeto educacional de proporções tão vastas tem muitas implicações, 0 que revela a importância das lutas culturais. E, por estranho que pareça, dá motivos para termos esperança, pois "se a direita pode fazer isso, a esquerda também pode fazer o mesmo", o que faz a leitura desse livro fundamental para todos aqueles que queiram construir as estratégias da resistência e da contra-hegemonia. 